\title{
Early school leaving: obstetrical and neonatal risks
}

\author{
Marie Valerie Rajaonarivony ${ }^{1}$, Tanjona A. Ratsiatosika ${ }^{1 *}$, Romuald Randriamahavonjy ${ }^{2}$, \\ Lantonirina Rainibarijaona $^{1}$, Jean Eustache Fanomezantsoa ${ }^{3}$, Aristide Andriamiandrisoa ${ }^{3}$, \\ Pierana Gabriel Randaoharison ${ }^{3}$
}

\author{
${ }^{1}$ Department of Medicine, Public Health Department, Antananarivo, Madagascar \\ ${ }^{2}$ Department of Obstetrics and Gynaecology, Soavinandriana Hospital Center of Faculty of Medicine Antananarivo, \\ Madagascar \\ ${ }^{3}$ Department of Medicine of Mahajanga, Zafisaona University Hospital Center Gabriel Mahajanga, Mother-Child \\ Complex, Madagascar
}

Received: 02 September 2020

Accepted: 07 October 2020

\section{*Correspondence:}

Dr. Tanjona A. Ratsiatosika,

E-mail: ratsiatosika.tanjona@gmail.com

Copyright: ( $)$ the author(s), publisher and licensee Medip Academy. This is an open-access article distributed under the terms of the Creative Commons Attribution Non-Commercial License, which permits unrestricted non-commercial use, distribution, and reproduction in any medium, provided the original work is properly cited.

\section{ABSTRACT}

Introduction: Maternal mortality remains very high in Madagascar. In addition, women's education level is low. The aim of this study is to determine the impact of the maternal educational level on the obstetrical and neonatal outcomes.

Methods: This is a retrospective analytical study of primiparae with seven years of study or less to patients with more than seven years of study at Zafisaona Gabriel Mahajanga university hospital center.

Results: Prematurity was higher in low-grade patients $(R R=2.6(1.04-6.51))$, and low birth weight was the leading cause of neonatal morbidity $(\mathrm{RR}=3.52)$. Pregnancy screening, maternal morbimortality, caesarean section, neonatal death and fetal intrauterine death were identical between the two groups.

Conclusions: Education has a positive impact on maternal health. An education on pregnancy outcomes should be done at school.

Keywords: Low birthweight, Newborn outcome, Maternal education, Pre-term

\section{INTRODUCTION}

Maternal mortality in Madagascar is among the highest. This rate amounts to 478 maternal deaths per 100,000 births for the period 2006-2013. ${ }^{1}$

Schooling remains very low. Illiteracy affects around $30 \%$ of $15-19$-year olds and around $40 \%$ of $15-24$-year olds. Among girls, $20.1 \%$ are uneducated between the ages of 20 and 24 . The secondary school attendance rate is only $54.4 \%$ in urban areas and $23.5 \%$ in rural areas. There is a high dropout rate. $82.7 \%$ have at most incomplete secondary education. ${ }^{2}$ Studies have been carried out to find out the correlation between the two parameters, but our study is the first to be carried out in Madagascar.

The objective of this study was to assess the neonatal and obstetrical prognosis of first-time mothers according to their level of study. Want to know if early school leaving is a factor for the poor prognosis of the pregnancy.

\section{METHODS}

Carried out a retrospective cohort study of first-time mothers admitted to the mother-child complex of the university hospital enter professor Zafisaona Gabriel 
Mahajanga over a period of three months from January 1 to March 31, 2015.

Collected data of patients who were hospitalized in the center. Included all primigravida with a monofetal pregnancy who gave birth in the center, beyond 22 WA (weeks of amenorrhea) and who had an education level of less than or equal to seven years. The control group is made up of an education level greater than seven years and matched according to the age of the groups of cases. Were excluded, patients who gave birth outside the hospital before admission, incomplete data.

Studied the following parameters: age, level of study, gestational age, pregnancy follow-up, delivery route, in utero death, neonatal morbidity and mortality (prematurity, respiratory distress syndrome, neonatal infection, admission to intensive care, fetal asphyxia by fifth minute APGAR score, fetal weight) and maternal mortality.

The data that we collected during our investigation were entered and analysed with Epi-info 7 software. For qualitative values, it was based on the chi-square study. The chosen significance level corresponded to a $\mathrm{p}=0.05$.

\section{RESULTS}

Had 57 patients with at most seven years of study. The average age was 21.44 years old. Among these, there was a case of fetal death in utero. In the control group, we had
76 patients who had at least seven years of study. Three intra-uterine fetal deaths were recorded in this group. There is no significant difference in age. Premature delivery affected one fifth of low-educated patients. $28 \%$ of patients were poorly monitored during pregnancy. The prevalence of preeclampsia and gestational diabetes was identical between 2 groups. Regarding maternal history, none of patients were smokers or diabetics (Table 1).

The rate of caesarean section and instrumental extraction were identical between the two groups. $29.82 \%$ was casualized in the group of patients with less than seven years of study (Table 2).

Fetal hypotrophy was higher in low-level patients. A quarter of the patients had a hypotrophic newborn. Acute respiratory distress syndrome (ARDS), admission to neonatal intensive care unit, occurrence of neonatal asphyxia, neonatal infection and early neonatal death were similar between the two groups (Table 3 ).

Not recorded any maternal deaths.

Prematurity was twice as high when the mother was less than seven years of study $(\mathrm{RR}=2.6$ [1.04-6.51]). Although the rate of poor pregnancy follow-up was higher in the case group, the risk was not significant (Table 4).

The risk of caesarean section and instrumental extraction were not different between the two groups (Table 5).

Table 1: Characteristics of pregnancy.

\begin{tabular}{|llll|}
\hline Charactristics & Level<7 years $\mathbf{N}(\%)$ & Level>7 years $\mathbf{N}(\%)$ & P value \\
\hline Age $($ year) & 21.44 & 21.45 & 0.86 \\
\hline Diabetes & 0 & 0 & - \\
\hline Smoking & 0 & 0 & - \\
\hline Prematurity & $12(21.43)$ & $6(8.22)$ & 0.01 \\
\hline Exceeding the term & $3(5.26)$ & $9(11.84)$ & 0.10 \\
\hline CPN<4 & $16(28.07)$ & $15(19.74)$ & 0.13 \\
\hline Pre-eclampsia & $6(10.53)$ & $6(7.89)$ & 0.6 \\
\hline
\end{tabular}

Table 2: Delivery route.

\begin{tabular}{|llll|}
\hline Characteristics & Leve<7 year N (\%) & Level $>$ year $\mathbf{N}(\%)$ & P value \\
\hline Caesarean & $17(29.82)$ & $27(3553)$ & 0.25 \\
\hline Instrumental extraction & $2(3.51)$ & $4(533)$ & 0.33 \\
\hline
\end{tabular}

Table 3: Fetal prognosis.

\begin{tabular}{|llll|}
\hline Characteristics & Level<7 year N (\%) & Level>7 year N (\%) & P value \\
\hline ARDS & $4(7.27)$ & $2(2.67)$ & 0.12 \\
\hline Neonatal resuscitation & $20(36.36)$ & $17(22.67)$ & 0.08 \\
\hline Neonatal asphyxia & $4(7.27)$ & $2(2.67)$ & 0.66 \\
\hline Death in utéro & $1(1.79)$ & $3(3.90)$ & 0.74 \\
\hline Early neonatal death & $1(1.79)$ & $1(1.37)$ & 0.82 \\
\hline Neonatal infection & $6(10.71)$ & $8(10.85)$ & 0.99 \\
\hline Hypotrophy & $13(23.21)$ & $5(6.58)$ & 0.009 \\
\hline
\end{tabular}


The risk of respiratory distress syndrome, neonatal resuscitation, neonatal asphyxia and early neonatal death, although high in patients with low education was not significant. However, fetal hypotrophy was three times higher in these patients (Table 6).

Table 4: Risk related to pregnancy.

\begin{tabular}{|lll|} 
Characteristics & RR & IC 95\% \\
\hline Prematurity & 2.6 & $(1.04-6.51)$ \\
\hline Exceeding the term & 0.44 & $(0.12-1.56)$ \\
\hline Antenatal care visit<4 & 1.42 & $(0.76-2.63)$ \\
\hline Pre-eclampsia & 1.33 & $(0.45-3.91)$ \\
\hline
\end{tabular}

Table 5: Risk of caesarean section and instrumental extraction in patients with less than 7 years of education.

\begin{tabular}{|lll|}
\hline Characteristics & RR & IC 95\% \\
\hline Cesarean & 0.83 & $(0.50-1.38)$ \\
\hline Instrumental extraction & 0.65 & $(012-3.46)$ \\
\hline
\end{tabular}

Table 6: Neonatal risk of patients with low level of study.

\begin{tabular}{|lll|}
\hline Characteristics & RR & IC 95\% \\
\hline ARDS & 2.72 & $(0.51-14.36)$ \\
\hline Neonatal resuscitation & 1.60 & $(0.93-2.76)$ \\
\hline Neonatal asphyxia & 2.72 & $(0.51-14.36)$ \\
\hline Death in utero & 0.45 & $(0.04-4.29)$ \\
\hline Early neonatal death & 1.3 & $(0.08-20.38)$ \\
\hline Neonatal infection & 0.97 & $(0.35-2.65)$ \\
\hline Hypotrophy & 3.52 & $(1.33-9.32)$ \\
\hline
\end{tabular}

\section{DISCUSSION}

Two facts stand out in our results. Patients who had a low level of education were more likely to give birth prematurely and have a low birth weight newborn. Our study still has its limits. This is a single-center study, in an urban population. As have described above, the low level of education is found especially in rural areas. The representativeness of the Malagasy population is impossible in view of these data. Nevertheless, this study allows us to have a reference to future studies.

Through this study, we were able to observe that the low level of education constitutes a risk factor for prematurity. The result confirms the data in the literature. Juarez and Park reported that primary education is a risk factor for prematurity. ${ }^{3,4}$

A study in Canada found a linear association between the level of education and the risk of prematurity. ${ }^{5}$ One of the limitations of this study lies in the fact that were unable to demonstrate the socio-economic level of parturients. In fact, precariousness constitutes a risk factor for complication of pregnancy, including prematurity. The improvement in the level of study makes it possible to reduce neonatal morbidity and mortality related to prematurity, which remains very high in Madagascar.

Education, in fact, improves the ability to adopt a healthy life to have a better life condition and reduce the risk of prematurity. Education during the prenatal period, the transmission of information is easier in patients who have a higher level of education. Access to education for women must be a priority to achieve the millennium development goal.

The risk of prolonged pregnancy is not significant. Juarez et al reported that patients with a primary education level have a higher risk of developing prolonged pregnancy. On the other hand, they included multiparas and pauci pares in their studies. ${ }^{3}$

Regarding the follow-up of pregnancy, although the attendance rate for the consultation of patients with low level of study is low, this difference was not significant. Another study conducted in China found the same result. Education level is not a risk factor for poor pregnancy monitoring. The term of the first antenatal visit is also not significant. However, according to the national millennium development goal survey in Madagascar, the fact that the provider is male is a barrier to care. Among women with no education, this proportion is $21 \%$ compared to $9 \%$ among those with a full secondary education. In the countryside this is especially the case, but in the big cities this obstacle would be less. Access to care is also difficult, especially for uneducated patients who often live far from health centers, especially in rural areas. $^{1}$

The caesarean section rate is not high in patients with low education levels. Tollanes, in his study of a Norwegian population, found that the rate of caesarean section was higher in patients with low education levels between 1967 and 2004. ${ }^{6}$

Between 1998 and 2000, Lee et al reported more Caesarean sections in patients under nine years of study. ${ }^{7}$ This difference could be explained on the one hand by the size of our sample, which is smaller. A larger-scale multicenter study would provide more information to be representative of the Malagasy population. On the other hand, access to peripartum analgesia is difficult or even impossible in our place of study. Patients with a more advanced level of study requested to be casualized to avoid pain associated with uterine contraction. This increases the rate of caesarean section in this population. Moreover, labor monitoring means such as fetal monitoring and scalp $\mathrm{pH}$ are not available. Caesarean section becomes a more common indication sometimes lacks true justification.

Patients with low education levels have a higher rate of preeclampsia, but this risk is not significant. Tollanes found the same result between 1967 and 1986. But from 1987, this risk becomes significant, only the academics 
involved less risk. But this study included the multiparas, the paucipares ${ }^{6}$. In this study, multiparas were excluded.

At birth, the risk of neonatal asphyxia was not different between the two groups. The study was based on the APGAR index. For Odd et al, in 2008, only university studies made it possible to reduce the risk of fetal asphyxia. Complete and incomplete secondary have the same risk of developing an APGAR of less than seven in the fifth minute. ${ }^{8}$

Another Swedish and Brazilian study found that the lower the level of study, the higher the risk of fetal asphyxia. $^{9,10}$ The low level of education is not a risk factor for neonatal death. In Congo, the result is identical. $^{11}$

In Brazil, the risk of neonatal death is correlated with maternal education level. The lower the level of study, the higher the risk of neonatal mortality. This risk is even higher in adolescent girls and in patients over 35 years of age. ${ }^{12}$ In Qatar, the risk of neonatal death is twice as high in patients with less than high school education. ${ }^{13}$ Other studies confirm this finding. ${ }^{15-16}$ This risk was not demonstrated in our study. This result can be explained by the small size of our sample. Multicenter studies with more cases could show the same result.

In this study, patients with incomplete secondary schooling had a high risk of neonatal hypotrophy and low birth weight. Studies in Asia have shown the same result. Patients with a higher level of study have a lower risk of developing a low birth weight. ${ }^{4,17}$

An Iranian study had shown a decrease in low birth weights in patients with a high level of study. This goes from $16.9 \%$ among the illiterate to $5.4 \% .^{18}$

A recent meta-analysis showed that high study level reduced the risk of low birth weight by $33 \%$, but in midlevel parturients this risk was not significant. ${ }^{19}$

A Swedish study had shown that women with a low level of education have a higher risk of low birth weight. ${ }^{20}$ This risk is all the more pronounced if the level of education is less than 8 years. $^{21}$ This risk is related to smoking, whereas in developed countries, parturients who smoke are mostly found among illiterate women. ${ }^{20,22}$ However, in our study, none of our patients is a smoker. The low level of education in itself is a risk factor for low birth weight.

Not had any maternal deaths, however according to Karlsen et al, primary level and illiteracy constitute a risk factor for maternal mortality risk. ${ }^{23}$ In Guinea, the maternal mortality rate is inversely proportional to education levels. The incidence ranges from $0.73 \%$ among the out-of-school to $0.00 \%$ among academics. ${ }^{24}$ The size of our sample and the fact that it is monocentric limits our study.
The high level of study has a positive impact on health. Advanced study-level patients are more independent in the decision-making process about their health. They often have a decent standard of living, allowing them to meet their needs. Education, health information would be easier. Level of study has been shown to be the primary determinant in predicting parturient health and fetal weight. $^{25,26}$

\section{CONCLUSION}

To conclude, we have seen that education has a positive impact on maternal and fetal health. The limitation of our study is the lack of knowledge of the socio-economic status of the patients. Prematurity and low birth weight, a source of high morbidity and mortality in Madagascar, could be reduced if girls and young women receive a good education. Offer a program on motherhood, the course of pregnancy and signs of complications in the school curriculum. A nationwide study should be carried out taking into account the various socio-economic parameters. The results will help guide the various health action programs to achieve the millennium development goal.

\section{Funding: No funding sources Conflict of interest: None declared \\ Ethical approval: The study was approved by the Institutional Ethics Committee}

\section{REFERENCES}

1. Instat. National survey on the follow-up of the Millennium Development Goals in Madagascar. Objective: 05. 2012-2013. 2013. Available at URL: http://madagascar.unfpa.org/sites/default/files/pubpdf/OMD_Resume.pdf. Accessed on 02 August 2020.

2. UNICEF, UNFPA. Young Malagasy: Facts and Figures. Synthetic report. 2011. Available at URL: http://www.unicef.org/madagascar/mg_media_pubs_ _jeunes_malgaches_faits_chiffres.pdf. Accessed on 02 August 2020.

3. Juarez S, Barbara A, Eugercios R, Ramiro-Farinas D, Viciana-Fernandez F. Maternal Education and Perinatal Outcomes Among Spanish Women Residing in Southern Spain (2001-2011). Matern Child Health J. 2013;18:1814-22.

4. Park MJ, Son M, Kim YJ, Paek D. Social Inequality in Birth Outcomes in Korea, 1995-2008. J Korean Med Sci, 2013;28(1):25-35.

5. Auger N, Abrahamowicz M, Park AL, Lo E. Extreme maternal education and preterm birth : timeto-event analysis of age and nativity-dependent risks. Ann Epidemiol. 2013;23:1-6.

6. Tollanes M, Thompson JMD, Daltveit AK, Irgens LM. Cesarean section and maternal education; secular trends in Norway, 1967-2004. Acta Obstet Gynecol. 2007;86:840-8. 
7. Lee S-I, Khang Y-H, Yun S, Jo M-W. Rising rates, changing relationships: caesarean section and its correlates in South Korea, 1988-2000. Int J Obstet Gynaecol. 2005;112(6):810-9

8. Odd DE, Doyle P, Gunnell D, Lewis G, Whitelaw A, Rasmussen F. Risk of low Apgar score and socioeconomic position: a study of Swedish male births. Acta Paediatr. 2008;97(9):1275-80.

9. Odd D, Lewis G, Gunnell D, Rasmussen F. Risk of low Apgar scores and socioeconomic status over a 30-year period. J Matern Fetal Neonatal Med. 2013;27(6):603-7.

10. Almeida NKO, Pedreira CE, Almeida R. Impact of maternal education level on risk of low Apgar score. Pub Heal. 2016;140:244-9.

11. Ntambue A, Malonga F, Dramaix-Wilmet $M$, Donnen P. Perinatal mortality: extent and causes in Lubumbashi, Democratic Republic of the Congo. Rev Epidemiol Sante Publique. 2013;61(6):519-29.

12. Fonseca SC, Flores PVG, Camargo Jr. KR, Pinheiro RS, Coeli CM. Maternal education and age: inequalities in neonatal death. Rev Saude Publica. 2017;51:94.

13. Ansari1 EA, Rahma SU. Level of Maternal Education is a Significant Determinant of Neonatal Survival: A PEARL Study Analysis. Journal of the College of Physicians and Surgeons Pakistan. 2015;25(2):151-3.

14. Arntzen A, Mortensen L, Schnor O, Cnattingius S, Gissler M, Andersen AM. Neonatal and postneonatal mortality by education: a population-based study of trends in the Nordic countries, 1981-2000. Eur J Pub Heal. 2008;18(3):245-51.

15. Bicego GT, Boerma JT. Maternal education and child survival: a comparative study of survey data from 17 countries. Soc Sci Med.1993;36:1207-27.

16. Cammu H, Martens G, Van Maele G, Amy JJ. The higher the educational level of the first-time mother, the lower the fetal and post-neonatal but not the neonatal mortality in Belgium (Flanders). Eur J Obstet Gynecol Reprod Biol. 2010;148:13-6.

17. Dai L-L, Mao Y-Y, Luo X-M, Shen YP. Prenatal Care in Combination with Maternal Educational Level Has a Synergetic Effect on the Risk of Neonatal Low Birth Weight: New Findings in a Retrospective Cohort Study in Kunshan City, China. PLoS ONE. 2014;9(11):e113377.
18. Jafari F, Eftekhar H, Pourreza A, Mousavi J. Socioeconomic and medical determinants of low birth weight in Iran: 20 years after establishment of a primary healthcare network. Pub Heal. 2010;124:153-8.

19. Silvestrin S, da Silva CH, Hirakata VN, Goldani AA, Silveira PP, Goldani MZ. Maternal education level and low birth weight: a meta-analysis. J Pediatr. 2013;89(4):339-45.

20. Nordström ML, Cnattingius S. Effects on birthweights of maternal education, socio-economic status, and work-related characteristics. Scand J Public Health. 1996;24(1):55-61.

21. Raum E, Arabin B, Schlaud M, Walter U, Schwartz FW. The impact of maternal education on intrauterine growth: a comparison of former West and East Germany. Int J Epidemiol. 2001;30(1):81-7.

22. Ergin I, Hassoy H, Tanik FA, Aslan G. Maternal age, education level and migration: Socioeconomic determinants for smoking during pregnancy in a field study from Turkey. Bio Med Centr Pub Heal. 2010;10:325.

23. Karlsen S, Say S, Souza JP, Hogue CJ, Calles DL, Gülmezoglu AM et al. The relationship between maternal education and mortality among women giving birth in health care institutions: Analysis of the cross sectional WHO Global Survey on Maternal and Perinatal Health. Bio Med Cent Pub Heal. 2011;11:606.

24. Diallo FB, Diallo AB, Diallo Y, Goma O, Camara Y, Cisse M, et al. Maternal Mortality and Lifestyle Risk Factors. Méd Afr Noire. 1998;45.

25. Maddah M, Karandish M, MohammadpourAhranjani B, Neyestani TR, Vafa R, Rashidi A. Social factors and pregnancy weight gain in relation to infant birth weight: a study in public health centers in Rasht. Iran Eur J Clin Nutr. 2005;59:1208-12.

26. Howard DL, Marshall SS, Kaufman JS, Savitz DA. Variations in low birth weight and preterm delivery among blacks in relation to ancestry and nativity: New York City, 1998-2002. Pediatrics. 2006;118(5):1399-405.

Cite this article as: Rajaonarivony MV, Ratsiatosika TA, Randriamahavonjy R, Rainibarijaona L, Fanomezantsoa JE, Andriamiandrisoa A, et al. Early school leaving: obstetrical and neonatal risks. Int J Reprod Contracept Obstet Gynecol 2020;9:5094-8. 